\title{
DOUTRINA
}

\section{PROFISSIONALIZAÇÃO DA FUNÇÃO PÚBLICA: A EXPERIÊNCIA BRASILEIRA}

\section{ROMEU FELIPE BaCELlar FILHO*}

I. Profissionalização da função pública e legitimação da administração pública - II. Constituição de 1988. Administração pública e princípio da impessoalidade - III. Profissionalização do servidor público, reforma administrativa e princípio da eficiência - IV. Profissionalização da função pública e princípio da acessibilidade aos cargos e empregos públicos

\section{Profissionalização da função pública e legitimação da administração pública}

No Direito brasileiro, a questão da profissionalização da função pública encontra-se intimamente ligada aos postulados constitucionais. Neste ensaio, o tema será tratado utilizando-se como referência a Administração Pública, aparelhamento do Estado que se encontra voltado, por excelência, à satisfação cotidiana das necessidades coletivas ${ }^{1}$, mas não tem legitimidade democrática direta, no máximo, em situações excepcionais, legitimidade apenas indireta. ${ }^{2}$

$\mathrm{O}$ art. $1^{\circ}$, da Constituição pátria estabelece que "A República Federativa do Brasil, formada pela união indissolúvel dos Estados e Municipios e do Distrito Federal, constitui-se em Estado Democrático de Direito e tem como fundamentos a soberania; a cidadania, a dignidade da pessoa humana; os valores sociais do trabalho e da livre iniciativa; o pluralismo político". Se a cidadania e a dignidade da pessoa humana constituem fundamentos do Estado, o interesse perseguido com

* Doutor em Direito do Estado. Professor da UFPR e da PUC/PR. Advogado.

1 Segundo Jorge MIRANDA, a função administrativa identifica-se, a partir do critério material, como a atividade de "satisfação constante e quotidiana das necessidades coletivas; prestação de bens e serviços." MIRANDA, Jorge. Manual de direito constitucional. Coimbra: Coimbra: 1997, p. 23. Tomo V: Actividade constitucional do Estado.

2 Os dirigentes são escolhidos por representantes do povo, geralmente, o Chefe do Poder Executivo (Presidente da República, Governadores e Prefeitos com aprovação do Poder Legislativo). 
o exercício da função administrativa deve encontrar seu princípio e fim no interesse dos próprios cidadãos, tanto numa perspectiva individual, quanto coletiva.

$\mathrm{Na}$ Itália, Andrea PUBUSA sustenta que, diante do princípio democrático e da soberania popular, inexistem interesses do Estado ou dos seus aparatos que não sejam instrumentais em relação à comunidade nem, enfim, decisões despidas de elementos de democraticidade. "O funcionário não serve o governo e comanda os cidadãos, mas serve exclusivamente os cidadãos". ${ }^{3}$ A Administração não cuida de interesses do Estado, mas de interesses dos cidadãos. ${ }^{4}$

O contexto espanhol não é diverso. Luciano PAREJO ALFONSO lembra que a condição democrática do Estado enquanto Estado de Direito constitui a própria base da Administração Pública. Bem por isso é exigida da organização e funcionamento do Estado em seu conjunto, a legitimação de todas as suas estruturas, e, portanto, de todo exercício de poder mediante sua recondução direta ou indireta ao povo. ${ }^{5}$ Sobre estas bases, a Administração Pública aparece como "poder estatal, igual ao Estado e ao mesmo tempo, organização (sujeito), função (atuação ou atividade) e ordenamento (dotado de uma economia e lógica próprias no seio do ordenamento geral do Estado). ${ }^{6}$

A Administração Pública legitima-se quando age em conformidade com o interesse público. Neste contexto, a profissionalização da função pública constitui instrumento de legitimação da Administração Pública brasileira perante o povo: (i) primeiro, para garantir a observância do princípio da igualdade na escolha de seus agentes, a partir de critérios que possibilitem a aferição daqueles mais preparados

3 O autor conclui que a administração não é "puissance pubblique", mas "servizio pubblico", na medida em que constitui um dos instrumentos principais do Estado para a realização da igualdade substancial, entendida como criação de igualdade de oportunidades e do princípio de solidariedade sobre o qual se funda o ordenamento jurídico italiano. : Somente" por causa destas sua função, a administração é dotada. nos casos previstos pela lei, de poderes autoritários. Mesmo assim, em geral, não é o "poder que age". sobretudo porque sempre age menos autoritariamente (prevalece na ação administrativa as prestaçôes e os serviços) e, secundariamente, porque quando age como autoridade, justifica-se tal poder em função de sua instrumentalidade em relação à utilidade social e ao interesse geral. PUBUSA, Andrea, op. cit., p. 48-49.

4 PUBUSA, Andrea. Diritti dei cittadini e pubblica amministrazione. Torino: G. Giappichelli Editore, 1996, p. 49. Sabino CASSESE e Rita PEREZ argumentam que a contraposição Estadosociedade civil, formulada no século XIX, é somente em parte um dado característico do ordenamento jurídico. A teoria de que o Estado, símbolo da autoridade, está em conflito permanente com a sociedade civil, constituída por cidadãos em luta pela liberdade, vem cedendo espaço a outras relaçōes que não são, necessariamente, de conflito. Ao lado da relação de oposição Estado-cidadão (que se reconduz, por exemplo, ao ceder de polícia), surge outro tipo de relação na qual o Estado desenvolve uma função não negativa, mas positiva, operando a favor dos particulares. Por exemplo, presta serviços públicos, concede financiamentos, entre outros. CASSESE, Sabino; PEREZ. Rita Mamuale di diritto pubblico. Roma: La Nuova Italia Scientifica, 1995, p. 84-85.

5 PAREJO ALFONSO, Luciano. La administración. Función pública. In: ENTERRIA, Eduardo Garcia; CLA VERO AREVALO, Manuel. (Directores). El derecho público de finales de siglo: una perspectiva iberomericana. Madrid; Civitas, 1997, p. 289.

6 PAREJO ALFONSO, op. cit., p. 291. 
para o exercício da profissão, e não num status atribuído em razão de um direito de nascença ou pela proximidade pessoal com os governantes; (ii) segundo, para dar cumprimento ao princípio da eficiência, de uma Administração capacitada a responder aos anseios coletivos mediante a prestação de serviços adequados.

\section{Constituição de 1988. Administração pública e princípio da impessoalidade}

A Constituição de 1988 inaugurou um capítulo dedicado à Administração Pública. Se uma das pedras de toques do Estado de Direito é a fixação de um regime jurídico administrativo ${ }^{7}$, a Lei Fundamental optou por consagrar um regime jurídico constitucional-administrativo, findado em princípios constitucionais expressos: legalidade, impessoalidade, moralidade, publicidade e eficiência (art. 37, caput). ${ }^{8}$

A disciplina constitucional administrativa traz, então, novos arsenais jurídicos para alteração do quadro tradicional de uma Administração Pública marcada pela pouca atenção dispensada aos direitos e garantias integrantes do patrimônio do cidadão-administrado. Afeiçoado à visão da legalidade a qualquer custo, com desconsideração a outros valores (como, por exemplo, o contido no princípio da confiança), o Administrador atuou, por muito tempo, coberto pelo manto da incontestabilidade do interesse público.

É verdade que não se trata de inovação propriamente dita, mas de recepção dos reclames da doutrina que construiu, desde cedo, vias alternativas para elidir a aplicação mecânica da legalidade. Implementou-se, assim, o princípio da finalidade pública segundo o qual, na estipulação pela lei, de competência ao Administrador Público, tem-se em foco um determinado bem jurídico eu deva ser suprido. $\mathrm{Na}$ apreciação da legalidade de um ato administrativo, é imperioso o exame da observância do escopo legal originário. Caio TÁCITO e Ruy CIRNE LIMA desenvolveram importante contribuição ao estudo da finalidade pública como parâmetro para avaliação da legalidade. ${ }^{9}$

A finalidade pública está compreendida no princípio da impessoalidade administrativa. Sua observância pela Administração previne o ato praticado de qualquer sentido de individualismo, posicionando-o em conformidade com o bem comum. Se o bem comum não se confunde com a soma dos interesses individuais, deles também

7 OVIEDO, Carlos Garcia. Derecho administrativo. 5. el. Madrid: Pizarro, 1955, p. 476.

8 O princípio da eficiência foi inserido pela recente reforma administrativa, operada pela Emenda Constitucional 19, de 1998.

9 Segundo Ruy CIRNE LIMA, "é o fim e não a vontade que domina todas as formas de administração (...) preside, destarte, no desenvolvimento da atividade administrativa do Poder Executivo - não o arbítrio que se funda na força - mas a necessidade que decorre da natural persecução de um fim." LIMA. Rui Cirne. Princípios de direito administrativo, 5. ed. São Paulo: RT, 1982, p. 21-22. Nesse sentido, Caio TÁCITO: "A regra de competência não é um cheque em branco". TÁCITO, Caio. Direito administrativo. 1. ed. São Paulo: Saraiva, 1975, p. 5. 
não prescinde. O Estado constitui um meio para que os indivíduos e as suas respectivas corporações possam atingir seus respectivos fins particulares. O sentido do bem comum é informado pelas necessidades de cada um e dá comunidade.

A expressão poder, estigmatizada durante o período ditatorial brasileiro, encontra-se melhor entendida como prerrogativa. Caso o Administrador Público utilize seu poder além dos limites que a lei lhe confere ou pratique desvio da finalidade pública, há abuso de poder na modalidade do excesso ou do desvio da finalidade. Se todo exercício de poder implica dose de sujeição, de coerção exercida pelo seu detentor sobre os destinatários, o poder não se auto-realiza, configura instrumento de trabalho adequado à realização das tarefas administrativas mediante o atendimento das aspirações coletivas. ${ }^{10}$

O $\S 1^{\circ}$, do art. 37, da Constituição Federal, ao tratar da publicidade dos atos, programas, obras, serviços e campanhas dos órgãos públicos, preceitua que esta deverá ter caráter educativo, informativo ou de orientação social, dela não podendo constar nomes, símbolos ou imagens que caracterizem promoção pessoal de autoridades ou servidores públicos. O mandamento - coerente com o princípio da impessoalidade - é claro e direto: o exercício de mandato, cargo, emprego ou função Pública configura atividade de natureza impessoal, não sendo lícito transformá-lo em veículo para o alcance de propaganda ou promoção pessoal. ${ }^{1 "} \mathrm{O}$ administrador que transgride este preceito convulsiona, desarmoniza e desacredita a ação administrativa.

A Administração Pública, como visto, tem por função precípua gerir a res pública, a coisa pública. Já se disse, com inteira razão, que a administração da coisa pública, até pela especialidade de sua atuação, é radicalmente diversa da administração da coisa privada. A razão é óbvia: o administrador privado, com a voluntariedade e liberdade próprias de quem é dono, age em consonância com o interesse particular. Dispõe dos bens e interesses, colimando um objetivo próprio, pessoal. Ao reverso, porque o administrador público encarrega-se de bens pertencentes à coletividade como um todo, os interesses em jogo são marcados pela indisponibilidade. Afinal, a ninguém é lícito ser desprendido com o que não lhe pertence.

O princípio da impessoalidade implica, para a Administração Pública, o dever de agir segundo regras objetivas e controláveis racionalmente. Desta forma, acentua-se a funcionalidade do agir administrativo e concretiza-se o princípio da igualdade.

10 "A atividade administrativa não é um fenômeno que se exerça pelo administrador parta os interesses da Administração Pública", nas palavras de Sérgio FERRAZ (Instrumentos de defesa do administrado. Revista de Direito Administrativo, Rio de Janeiro, n. 165, p. 22, jul./set. 1986).

11 Como bem coloca Carmem Lúcia ANTUNES ROCHA, “o princípio da impessoalidade traz o sentido de ausência de rosto do administrador público; de outro, significa, a ausência de nome do administrado." ROCHA, Carmem Lúcia Antunes. O princípio constitucional da igualdade. Belo Horizonte: Editora Lê, 1990. p. 85. 


\section{Profissionalização do servidor público, reforma administrativa e princípio da eficiência}

O princípio da eficiência foi inserido pela Emenda Constitucional n. 19 de 1998 entre os princípios constitucionais da Administração Pública elencados no caput, do art. 37, da CF. O princípio não é inédito no direito comparado: a Constituição Espanhola de 1976 já o prevê, assim também as Leis de Procedimento Administrativo dos países vizinhos do Brasil, como é o caso, por exemplo, da Argentina, Uruguai e Peru (fala-se em princípio da eficácia). Também não é inédito na doutrina brasileira: Hely LOPES MEIRELLES já tratava do "dever de eficiência", consagrado no Decreto-Lei 200167 e correspondente ao "dever de boa administração" da doutrina italiana. ${ }^{12}$

A licitação e o concurso público configuram, no Brasil, os dois principais instrumentos de garantia da profissionalização da atividade administrativa. Ambos os certames destinam-se à seleção de agentes qualificados, do ponto de vista técnico, para o desempenho de atividades inerentes à Administração Pública. A licitação como mecanismo para seleção de particulares em colaboração com a Administração Pública ${ }^{13}$ (notadamente concessionários e permissionários de serviços públicos) e o concurso público, para seleção de servidores públicos, pessoas físicas que prestam serviços ao Estado com vínculo empregatício e mediante remuneração paga pelos cofres públicos.

A Constituição Federal impõe, no art. 37, XXI a obrigatoriedade de licitação para as contratações administrativas, ressalvados os casos especificados na legislação. ${ }^{14}$ Esta mesma exigência é reiterada para as concessões e permissões de serviços públicos no art. $175^{15}$, com linguagem enérgica, ao estabelecer que serão "sempre" precedidas de licitação. Ainda, o inc. IV, do art. 175 determina que a Lei deve dispor sobre "a obrigação de manter serviço adequado". ${ }^{16}$

\section{MEIRELLES.}

13 Embora exerçam atividades administrativa, não pertencem aos quadros dos servidores públicos, porque não têm vinculo empregatício com o Estado.

14 Art. 37, inc. XXI: "Ressalvados os casos especificados ira legislarảo, as obras, serviços, compras e alienações serão contratadas mediante processo de licitação pública que assegure igualdade de condições a todos os concorrentes, mantidas as condições efetivas da proposta, nos termos da lei, o qual somente permitirá exigências de qualificação técnica e econômica indispensáveis à garantia do cumprimento das obrigações."

15 Art. 175. "Incumbe ao Poder Público, na forma da lei, diretamente ou sob regime de concessão ou permissão. sempre através de licitação, a prestação de serviços públicos."

16 Por sua vez, a Lei 8.987/95 define serviço adequado como aquele "que satisfaz as condiçōes de regularidade, continuidade, eficiência, segurança, atualidade, generalidade, cortesia na sua prestação e modalidade das tarifas" ( $\$ 1^{\circ}$, do art. $6^{\circ}$ ). Como observa Celso Antônio BANDEIRA DE MELLO, "a licitação visa alcançar duplo objetivo: proporcionar às entidades governamentais possibilidades de realizarem o negócio mais vantajoso (pois a instauração de competição entre ofertastes preordena-se a isto) e assegurar ao administrados ensejo de disputarem a participação nos negócios que as pessoas governamentais pretendem realizar com os particulares." (BANDEIRA DE MELLO, Celso Antônio. Curso de Direito administrativo. 13. ed. São Paulo: Malheiros, 2001. p. 471.) 
De outro lado, o inciso II, do art. 37, consagra o princípio da acessibilidade aos cargos e empregos públicos mediante concurso público como regra, prevendo uma exceção: a livre nomeação e exoneração para os cargos em comissão: " a investidura em cargo ou emprego público depende de aprovação prévia em concurso público de provas ou de provas e títulos, de acordo com a natureza e a complexidade do cargo ou emprego, na forma prevista em lei. ressalvadas as nomeações para cargo em comissão declarado em lei de livre nomeação e exoneração."

O princípio da eficiência constitui peça fundamental da reforma administrativa iniciada nos anos 90 da Administração Pública Federal. "Uma Administração Pública eficiente" é o título do sexto Caderno do Ministério da Administração Federal e Reforma do Estado ${ }^{17}$, que tem início com a seguinte frase emblemática: "O objetivo da reforma é permitir que a administração pública se torne mais eficiente e ofereça ao cidadão mais serviços, com mais qualidade." 18

A profissionalização do servidor público substancia um ponto forte da reforma administrativa operada pela Emenda Constitucional n. 19, de 4 de junho de 1998. O preparo técnico para o desempenho de cargo, emprego ou função pública é condição sine qua non para avaliar a eficiência do servidor público. Para além do concurso público, a Constituição consagra vários institutos dispostos àquela finalidade:

(i) $\mathrm{O}$ inciso $\mathrm{V}$, do art. 37, estabelece que as funções de confiança serão exercidas exclusivamente por servidores ocupantes de cargo efetivo (legitimados pelo crivo do concurso público) prevendo, ainda, restrições no tocante aos cargos em comissão (em que a investidura não depende de concurso público): devem ser preenchidos por servidores de carreira (concursados) conforme percentual mínimo previsto em lei e limitam-se às atribuições de chefia, direção e assessoramento.

(ii) O caput, do art. 39 prevê a instituição pela União, Estado, Distrito Federal e Municípios do Conselho de Política de Administração e Remuneração de Pessoal, a ser integrado por servidores designados pelos respectivos Poderes (Legislativo, Executivo e Judiciário).

(iii) $\mathrm{O} \S 2^{\circ}$, do art. 39, estabelece que a União, os Estados e o Distrito Federal deverão manter escolas de governo para a formação e o aperfeiçoamento dos servidores públicos, constituindo-se a participação nos cursos um dos requisitos para a promoção na carreira.

(iv) $\mathrm{O} \S 7^{\circ}$, do art. 39, dispõe que Lei da União, dos Estados, do Distrito Federal e dos Municípios disciplinará a aplicação de recursos orçamentários provenientes da economia com despesas correntes em cada órgão, autarquia e fundação, para aplicação no desenvolvimento de programas de qualidade produtividade, treinamento e desenvolvimento, modernização, re-aparelhamento e racionalização do serviço público, inclusive sob a forma de adicional ou prêmio de produtividade.

17 Ministério já extinto.

18 Cadernos MARE da Reforma do Estado. Brasília: Ministério da Administração Federal e Reforma do Estado, 1998, n. 6. p. 7. 
(v) $\mathrm{O} \S 4^{\circ}$, do art. 41 passa a contemplar a obrigatoriedade de avaliação especial de desempenho por Comissão instituída para essa finalidade como condição para a aquisição da estabilidade.

De outro lado, a Emenda Constitucional n 19/1998 prevê hipóteses específicas para responsabilização do servidor por desempenho funcional ineficiente, para além da apuração e aplicação de sanções disciplinares relacionadas a deveres e proibições funcionais:

(i) $\mathrm{O} \S 1^{\circ}$, inc. III, do art. 41 prevê a possibilidade de perda do cargo pelo servidor estável mediante procedimento de avaliação periódica de desempenho, na forma de lei complementar, assegurada ampla defesa.

(ii) O parágrafo único, do art. 247 dispõe sobre a perda do cargo do servidor público estável que, em decorrência das atribuições do seu cargo efetivo desenvolva atividades exclusivas de Estado, na hipótese de insuficiência de desempenho, assegurados o contraditório e a ampla defesa.

(iii) A participação do usuário na Administração Pública direta e indireta deverá ser disciplinada por lei específica. $O \S 3^{\circ}$, do art. 37 determina que esta lei deverá regular especialmente as reclamações relativas à prestação de serviços públicos em geral, asseguradas a manutenção de serviços de atendimento ao usuário e a avaliação periódica, externa e interna, da qualidade dos serviços; o acesso dos usuários a registros administrativos e a informações sobre atos de governo, observado o disposto no art. $5^{\circ}, \mathrm{X}$ e XXXIII; a disciplina da representação contra o exercício negligente ou abusivo de cargo, emprego ou função na administração pública.

\section{Profissionalização da função pública e princípio da acessibilidade aos cargos e empregos públicos}

Cumpre tecer algumas considerações a respeito da profissionalização da função pública e o princípio do concurso público. Para José AFONSO DA SILVA, "o princípio da acessibilidade aos cargos e empregos públicos visa essencialmente realizar o princípio do mérito que se apura mediante investidura por concurso público de provas ou de provas e títulos (art. 37, II)." 19

Como bem referiu o Ministro Celso de Mello, "o concurso, público representa garantia concretizadora do princípio da igualdade. O respeito efetivo à exigência de prévia aprovação em concurso publico qualifica-se, constitucionalmente, como paradigma de legitimação ético jurídica, da investidura de qualquer cidadão em cargos, funções ou empregos públicos, ressalvadas as hipóteses de nomeação para cargos em comissão (CF, art. 37, II). A razão subjacente ao postulado do concurso público traduz-se na necessidade essencial de o Estado conferir efetividade ao princípio constitucional de que todos são iguais perante a lei, sem distinção de qualquer natureza, vedando-se, desse modo, a prática inaceitável de o Poder Público conceder

19 SILVA, José Afonso. Curso de direito constitucional. 10. ed. São Paulo; Malheiros, 1995. p. 624. 
privilégios a alguns ou de dispensar tratamento discriminatório e arbitrário a outros." 20 Afinal, como ressalta o Ministro Sepúlveda PERTENCE, "acima do problema individual do direito subjetivo de acesso à função pública, situa-se o da incompatibilidade com o regime democrático de qualquer sistema que viabilize a cooptação arbitrária, como base de composição de um dos poderes do Estado." ${ }^{21}$

A função é o meio pelo qual se concretizam as atribuições do cargo ou do emprego público ${ }^{22}$. Embora a função englobe a competência, com ela não se confunde. Enquanto a competência designa um círculo de atribuições inerentes ao cargo ou emprego, na função estão também compreendidas as proibições. Além das obrigações de fazer (competência), as obrigações de não fazer (proibições).

Antes da Constituição de 1988, o concurso público era exigido somente para a primeira investidura em cargo público, o que permitia a transposição ou ascensão funcional, ato pelo qual o servidor passava de um cargo a outro de conteúdo ocupacional diverso, mediante concurso interno. Tratava-se de um sistema de mérito no serviço público, que premiava os servidores que buscavam o aprimoramento na profissão. Todavia, o Supremo Tribunal Federal, ao interpretar o inc. II, do art. 37, da Constituição, entendeu banida do ordenamento jurídico a ascensão funcional como forma de provimento de cargo público efetivo. ${ }^{23}$ Por construção jurisprudencial, acabou-se por eliminar um dos mais importantes institutos de profissionalização do servidor público.

O Supremo Tribunal Federal deixou aberta, no entanto, a possibilidade do Legislador criar um sistema de promoção na mesma carreira (sem mudar o cargo e a referência, o servidor passa para outro grau, razão pela qual a promoção dá-se no plano horizontal), tendo em vista que o $\S 2^{\circ}$, do art. 39 , da CF alude expressamente à participação nos cursos de formação e aperfeiçoamento como um dos requisitos para a promoção na mesma carreira. ${ }^{24}$ Contudo, os legisladores não tem se preocupado em implementar um sistema de promoção nas carreiras públicas.

20 Supremo Tribunal Federal. Ação Direta de Inconstitucionalidade n. 2.364-AL. Julgamento: Tribunal Pleno.

21 Supremo Tribunal Federal. Recurso extraordinário n. 1946571RS. Relator: Ministro Sepúlveda Pertence Tribunal Pleno.

22 Os empregos públicos são adequados à organização dos servidores das entidades da Administração indireta (sociedades de economia mista e empresas públicas) contratados no regime da legislação trabalhista (art. $173, \$ 1^{\circ}, \mathrm{CF}$ ).

23 Nesse sentido: Supremo Tribunal Federal. ADIn 2433IRN. Relator: Ministro Maurício Corrêa., DJU 24.8.01. Tribunal Pleno. Unânime.

24 "MANDADO DE SEGURANÇA. DIREITO ADMINISTRATIVO. PROGRESSÃO FUNCIONAL DE CARREIRA DE NÍVEL MÉDIO PARA OUTRA DE NÍVEL SUPERIOR. PROVIMENTO DERIVADO BANIDO DO ORDENAMENTO JURÍDICO. NECESSIDADE DE CONCURSO PÚBLICO. Jurisprudência pacificada no STF acerca da impossibilidade de provimento de cargo público efetivo mediante ascensão ou progressão. Formas de provimento - derivado banidas pela Cartat de 1988 do ordenamento jurídico. A investidura de servidor efetivo em outro cargo depende de concurso público (CF, art. 37, II) ressalvadas as hipóteses de promoção na mesma carreira de cargos em comissão." Supremo Tribunal Federal. Mandado de Segurança n. 23670/DF. Relator: Ministro Maurício Corrêa. Tribunat Pleno. 
Polêmica continua sendo a possibilidade constitucional do acesso, forma de provimento pela qual o servidor passa para cargo de maior grau de responsabilidade e maior complexidade de atribuições, dentro da carreira a que pertence (plano vertical). Sobre este instituto, lúcida a ponderação do Ministro Marco Aurélio de Mello, ainda que anteriormente à Emenda Constitucional n. 19/98: "Dizer-se, a esta altura, que a passagem de um para outro cargo da mesma carreira somente é possível pela via do concurso público é afastar as perspectivas do servidor quando do ingresso no serviço público, esvaziando-se o significado do artigo 39 da Constituição Federal no que, ao prever a adoção do regime jurídico único, alude ao implemento do plano de carreira. ${ }^{25}$ Proibir o acesso funcional importa desestímulo dos servidores públicos, com graves prejuízos para a Administração Pública. A impossibilidade de alcançar cargos mais elevados, na carreira, não condiz com a necessidade de estimular o aprimoramento profissional necessário à prestação de serviços adequados pela Administração Pública.

A implementação de um sistema de mérito no funcionalismo público é emergencial. A profissionalização da função pública exige não somente o fortalecimento do concurso público (e a necessidade de se privilegiar interpretações restritivas quanto aos cargos em comissão que constituem exceção à regra do concurso), como também um adequado plano legislativo de carreira, em todos os níveis da Federação (União, Estados, Distrito Federal e Municípios).

25 Supremo Tribunal Federal. Ação direta, de inconstitucionalidade n. 23 1. Revista de Direito Administrativo. Rio de Janeiro: Renovar, n. 191. 


\section{Apontamentos sobre a Reforma Administrativa}

Diogo de Figueiredo Moreira Neto

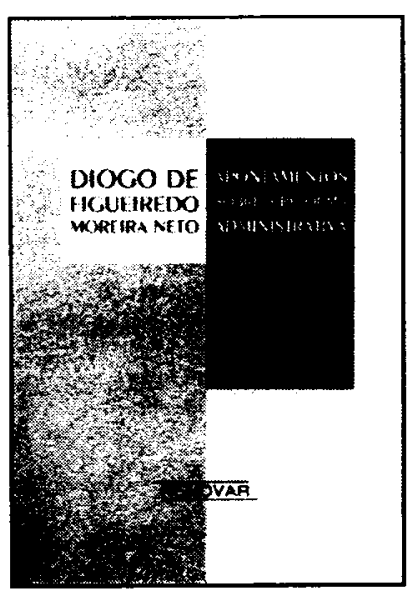

Este livro mantém-se introdutório e despretensioso, oferecendo apenas um guia de anotações, por entender que estas devam ser apenas um início e uma abertura de uma necessária e ponderável contribuição doutrinária e jurisprudencial que deverão amadurecer no estudo e no debate e haverāo de ser fundamentais para sua serena e correta aplicação, não só em benefício do aperfeiçoamento como, e principalmente, da segurança jurídica.

Ref. 0214

Brochura

Form. 14x21 1999

\section{A Reconstrução dos Direitos Humanos da Tributação}

Nesta obra, o autor retorna à análise do fenômeno tributário, agora na vertente dos Direitos Humanos, a partir dos eventos que se seguiram à Revolução Francesa, elaborando uma inédita Teoria Geral da Tributaçāo de profunda importância para a emancipação da Democracia.

Ref. 0143

Form. 14x21
Brochura 1997
Alberto Nogueira

Alberto Nogueira

A RECONSTRUÇÃO DOS DIREITOS HUMANOS DA TRBOMA:

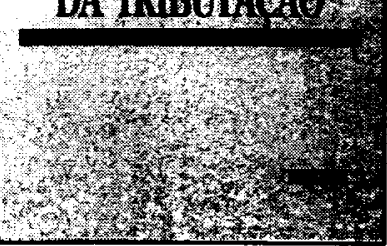

